\title{
PEP-1-SOD1 fusion proteins block cardiac myofibroblast activation and angiotensin Il-induced collagen production
}

\author{
Li-Guo Tan ${ }^{1,2 \dagger}$, Jun-Hui Xiao ${ }^{2 \dagger}$, Dan-Li Yu³ ${ }^{3}$ Lei Zhang ${ }^{1}$, Fei Zheng ${ }^{1}$, Ling-Yun Guo ${ }^{1}$, Jian-Ye Yang ${ }^{1}$, Jun-ming Tang ${ }^{1,2}$,
} Shi-You Chen ${ }^{4}$ and Jia-Ning Wang ${ }^{1,2^{*}}$

\begin{abstract}
Background: Oxidative stress is closely associated with cardiac fibrosis. However, the effect of copper, zincsuperoxide dismutase (SOD1) as a therapeutic agent is limited due to the insufficient transduction. This study was aimed to investigate the effect of PEP-1-SOD1 fusion protein on angiotensin II (ANG II)-induced collagen metabolism in rat cardiac myofibroblasts (MCFs).

Methods: MCFs were pretreated with SOD1 or PEP-1-SOD1 fusion protein for $2 \mathrm{~h}$ followed by incubation with ANG II for $24 \mathrm{~h}$. Cell proliferation was measured by Cell Counting Kit-8. Superoxide anion productions were detected by both fluorescent microscopy and Flow Cytometry. MMP-1 and TIMP-1 were determined by ELISA. Intracellular MDA content and SOD activity were examined by commercial assay kits. Protein expression was analyzed by western blotting.

Results: PEP-1-SOD1 fusion protein efficiently transduced into MCF, scavenged intracellular $\mathrm{O}_{2}^{-}$, decreased intracellular MDA content, increased SOD activity, suppressed ANG Il-induced proliferation, reduced expression of TGF- $\beta 1$, a-SMA, collagen type I and III, restored MMP-1 secretion, and attenuated TIMP-1 secretion.

Conclusion: PEP-1-SOD1 suppressed MCF proliferation and differentiation and reduced production of collagen type I and III. Therefore, PEP-1-SOD1 fusion protein may be a potential novel therapeutic agent for cardiac fibrosis.
\end{abstract}

Keywords: Cell-penetrating peptide, Copper, Zinc-superoxide dismutase, Cardiac myofibroblasts, Collagen

\section{Background}

Cardiac fibrosis, characterized by abnormal proliferation of cardiac myofibroblasts (MCF) and excessive deposition of extracellular matrix (ECM), is a leading cause of progressive deterioration of cardiac function and structure in a number of chronic heart diseases including hypertension, coronary heart diseases, and cardiomyopathies. However, no effective therapeutics is currently available. MCFs are the most prevalent cell type in the heart that plays pivotal roles in cardiac fibrosis. Under a number of stimuli such as cytokines (e.g., TGF- $\beta 1$, IL-1, or endothelin-1),

\footnotetext{
*Correspondence: rywjn@vip.163.com

${ }^{\dagger}$ Equal contributors

'Institute of Clinical Medicine, Renmin Hospital, Hubei University of Medicine, Shiyan, Hubei 442000, P. R. China

2Department of Cardiology, Renmin Hospital, Hubei University of Medicine, Shiyan, Hubei 442000, P. R. China

Full list of author information is available at the end of the article
}

hormones (e.g., angiotensin II (Ang II) or noradrenaline), and mechanical stretch, cardiac fibroblasts can be converted into MCFs exhibiting increased migratory, proliferative, and secretion properties. MCFs are the major source of ECM in the heart with cardiac fibrosis [1].

A growing number of studies have suggested that oxidative stress induced by reactive oxygen species (ROS). (ROS) is associated with cardiac fibrosis. ROS is significantly elevated in hearts of patients and animal models with cardiac fibrosis [2, 3]. Increased ROS triggers a series of cellular events such as differentiation, proliferation, secretion and gene expression. The elevated ROS also increases myofibroblast proliferation and ECM synthesis $[4,5]$. Moreover, ROS reduces ECM degradation by regulating the level of matrix metalloproteinases (MMPs) and tissue inhibitor of metalloproteinases (TIMPs) [6]. Superoxide dismutases (SOD) are important antioxidant 
enzymes that accept an electron from superoxide anion $\left(\mathrm{O}^{2-}\right)$ and $\mathrm{H}_{2} \mathrm{O}$ to generate hydrogen peroxide $\left(\mathrm{H}_{2} \mathrm{O}_{2}\right)$. Cytoplasm-located SOD1 is the major isoform of SODs in mammalian, and angiotensin II (ANG II)-induced ROS has been found to down-regulate SOD1 activity in rat MCF [7]. These studies suggest that SOD1 is a potential target for preventing cardiac fibrosis. However, exogenous SOD1 cannot be delivered into cells to block oxidative stress because of the lack of specific membrane channel or receptor for SOD1.

PEP-1 ((KETWWETWNTTEWSQPKKKRKV), a novel peptide carrier designed by Morris group [8], consists of three domains: a hydrophobic tryptophan rich motif (KET WWETWWTEW), a spacer (SQP), and a hydrophilic lysine-rich domain (KKKRKV). A number of proteins fused with PEP-1 have been efficiently delivered into cells or tissues. Our previous studies have shown that PEP-1-SOD1 fusion protein can be transduced into myocardial and cerebral tissues to protect against oxidative stress induced by ischemia-reperfusion injury [9-11]. In the present study, we found that PEP-1-SOD1 fusion protein, when transduced into rat cardiac myofibroblast, mediates collagen metabolism by blocking ANG II-induced ROS production. Since collagen deposition is a major factor causing fibrosis, PEP-1-SOD1 fusion protein may be a potential therapeutic agent for treating cardiac fibrosis.

\section{Methods}

\section{Expression and purification of SOD1 and PEP-1-SOD1 fusion protein}

SOD1 and PEP-1-SOD1 infusion protein were expressed and purified as previously described $[9,10]$. Briefly, two prokaryotic expression plasmids, pET15b-SOD1 and pET15b-PEP-1-SOD1, were constructed with TA-cloning method. The two recombinant plasmids were respectively transformed into E. Coli BL21 (DE3) bacteria (Novagen, USA). Bacteria that have been successfully transformed were grown in $100 \mathrm{ml} \mathrm{LB}$ medium containing $100 \mathrm{ug} / \mathrm{ml}$ ampicillin at $37{ }^{\circ} \mathrm{C}$ to an $\mathrm{OD}_{600}$ value of $0.5-1.0$ and induced by $0.83 \mathrm{mM}$ isopropyl- $\beta$-D-thiogalactoside (IPTG) (Promega, USA) at $25^{\circ} \mathrm{C}$ for $12 \mathrm{~h}$. The bacteria were then harvested and lysed by sonication at $4{ }^{\circ} \mathrm{C}$ in a binding buffer $(5 \mathrm{mM}$ imidazole, $500 \mathrm{mM} \mathrm{NaCl}, 20 \mathrm{mM}$ Tris- $\mathrm{HCl}$, $\mathrm{pH}$ 7.9) for $30 \mathrm{~min}$. The supernatant after centrifugation was loaded onto a $\mathrm{Ni}^{2+}$-nitrilotriacetic acid sepharose affinity column (Qiagen, USA) under native conditions. The column was washed with 10 volumes of the binding buffer and 6 volumes of wash buffer $(60 \mathrm{mM}$ imidazole, $500 \mathrm{mM} \mathrm{NaCl}, 20 \mathrm{mM}$ Tris-HCl, $\mathrm{pH}$ 7.9), and eluted by an eluting buffer ( $1 \mathrm{M}$ imidazole, $500 \mathrm{mM} \mathrm{NaCl}, 20 \mathrm{mM}$ Tris- $\mathrm{HCl}, \mathrm{pH}$ 7.9). The fusion proteins were collected at the peak of $\mathrm{OD}_{280}$. The salts of fusion proteins were removed using a PD-10 column, and the fusion proteins were identified by SDS-PAGE and western blot analysis.
The protein concentration was assayed with $\mathrm{BCA}$ assay kit (Beyotime Institute of Biotechnology, China).

\section{Isolation and culture of primary rat cardiac MCFs}

All animal procedures were carried out in accordance with Regulations of Good Laboratory Practice for non-clinical laboratory studies of drugs issued by the State Food and Drug Administration of China, and the experimental protocol was approved by the Institutional Animal Care and Use Committee of Hubei University of Medicine. Cardiac ventricular myofibroblasts were obtained from male adult Sprague-Dawley rats. Briefly, adult rats were sacrificed by cervical dislocation under ether anesthesia, and the hearts were excised, rinsed with growth media (Dulbecco's modified essential media (DMEM) supplemented with $10 \%$ fetal bovine serum, $100 \mathrm{U} / \mathrm{ml}$ penicillin $\mathrm{G}$ and $100 \mu \mathrm{g} / \mathrm{ml}$ streptomycin) and trimmed of connective tissue and fat. The atria were removed, and the ventricle was cut into small pieces with about $1 \mathrm{~mm}^{3}$ size. The ventricle pieces were transplant into $25 \mathrm{~cm}^{2}$ culture flasks, allowed to dry briefly and then flooded with $5 \mathrm{ml}$ growth media. Culture flasks were then incubated at $37^{\circ} \mathrm{C}$ with $5 \% \mathrm{CO}_{2}$ balanced air for 1 week. Cell outgrowths from explanted tissues were digested and passaged when grew to $70 \%$ confluent. The growth media with suspended cells were discarded after $90 \mathrm{~min}$, the fresh growth media was added, and the adhered cells were cardiac myofibroblasts. Cells from passages 1-6 were used in this study. Cells from passage 2 were detected by immunofluorescent staining with von Willebrand factor (VWF), desmin, and vimentin antibodies for identification of endothelial cells, muscle cells and fibroblasts, respectively, as previously described [12].

\section{Transduction of PEP-1-SOD1 protein into MCF}

MCF were grown to confluence on 6-well cell culture plates, and then pretreated with PEP-1-SOD1 fusion proteins or SOD1 proteins at different dosages $(0-4 \mu \mathrm{mol} / \mathrm{L})$ for $0-24 \mathrm{~h}$. Cells were then washed with phosphatebuffered saline (PBS), harvested and lysed for western blot or enzyme activity assay. The SOD activity was measured with a SOD Activity Assay Kit by following the manufacture's protocols (JianCheng Bioengineering Institute, China). To further confirm transduction of PEP-1-SOD1 fusion proteins, MCF were cultured to confluence in 24well plates, pretreated with $2 \mu \mathrm{mol} / \mathrm{L}$ PEP-1-SOD1 fusion proteins or SOD1 proteins for $2 \mathrm{~h}$, washed twice with $1 \mathrm{x}$ PBS, and immunostained with anti-His-tag antibody.

\section{Measurement of malondialdehyde (MDA) content, superoxide dismutase (SOD) activity, and superoxide anion $\left(\mathrm{O}_{2}^{-}\right)$}

MDA reflects the peroxide production of cell membrane lipids caused by oxidative stress. MDA content and SOD activity were used as indicators of oxidative damage. The 
MDA content and SOD activity in MCF were determined with a MDA Assay Kit and SOD Activity Assay Kit (JianCheng Bioengineering Institute, China), respectively. The levels of $\mathrm{O}_{2}^{-}$in cells were detected with oxidation-sensitive fluorescent probe dihydroethidium (DHE) (Beyotime Institute of Biotechnology, China) and measured with fluorescent microscopy and flow cytometry as described previously [13].

\section{MCF proliferation assay}

To investigate the effect of PEP-1-SOD1 on MCF proliferation induced by Ang II, MCF were cultured in 96well cell culture plates, and divided into six groups: vehicle-treated (CTL), SOD1 with vehicle, PEP-1-SOD1 with vehicle, Ang II-treated group, SOD1 with Ang II, and PEP-1-SOD1 with Ang II. The cells were starved in serum-free DMEM for $24 \mathrm{~h}$ to mimic the ischemic condition (depletion of nutrients) followed by pretreatment with or without $2 \mu \mathrm{mol} / \mathrm{L}$ of PEP-1-SOD1 or SOD1 for $2 \mathrm{~h}$. The media were replaced with DMEM containing $10 \%$ fetal bovine serum to mimic the reperfusion condition. The cells were then incubated with vehicle or $100 \mathrm{nmol} / \mathrm{L}$ Ang II for 24 h. MCF proliferation was assayed with Cell Counting Kit-8 (CCK-8) by following the manufacture's protocols (Beyotime Institute of Biotechnology, China).

\section{Immunofluorescent cytochemistry}

Fluorescent immunocytochemistry was performed on 24-well cell culture plates as previously described [9]. Briefly, after treatment as described above, cells were washed twice with $1 \times$ PBS, fixed with $1 \%$ paraformaldehyde for $15 \mathrm{~min}$ at room temperature, and incubated with rabbit anti-His-tag (diluted 1:100), goat anti-VWF (diluted 1:100), mouse anti-desmin (diluted 1:100), or mouse antivimentin antibody (diluted 1:100) (Santa Cruz Biotechnology, USA) at $4{ }^{\circ} \mathrm{C}$ overnight. Cells were then incubated with FITC-conjugated second antibodies (diluted 1:250) (Zhongshan Biotechnology, China) at $25^{\circ} \mathrm{C}$ for $2 \mathrm{~h}$. Nuclei were stained with DAPI (Sigma, USA). The results were observed under a fluorescent microscope (Nikon, Japan).

\section{Western blot}

MCF were harvested and lysed in a lysis buffer. Western blots were performed as previously described [14]. Equal amount of proteins from each sample were subjected to SDS-PAGE, and then transferred to nitrocellulose membranes. The membranes were blocked with $5 \%$ BSA and incubated at $4{ }^{\circ} \mathrm{C}$ overnight with specific primary antibodies: rabbit anti-PCNA (diluted 1:100), rabbit His-tag (diluted 1:100), goat anti-collagen I (diluted 1:200), mouse anti- $\alpha$-SMA (diluted 1:100), rabbit antiTGF- $\beta 1$ (diluted 1:200), goat anti-gp91 ${ }^{\text {phox }}$ (diluted 1:200) (Santa Cruz Biotechnology, USA), or mouse anti-collagen III (diluted 1:200) (Sigma, USA). The horseradish peroxidase-conjugated second antibodies (diluted 1:5000) (Zhongshan Biotechnology, China) were incubated for $2 \mathrm{~h}$ at room temperature. Proteins were detected by ECL detection system.

\section{MMP-1 and TIMP-1 expression assay}

The content of matrix metalloproteinase-1 (MMP-1) or tissue inhibitor of metalloproteinase-1 (TIMP-1) in MCFconditioned media was examined using rat MMP-1 and TIMP-1 ELISA kits (BioSwamp, China).

\section{Statistical analyses}

All dates are expressed as mean \pm SD. Differences between groups were analyzed by one-way analysis of variance. $P<0.05$ was considered statistically significant difference.

\section{Results}

\section{Transduction of PEP-1-SOD1 fusion protein into cardiac} MCF

SOD1 and PEP-1-SOD1 fusion proteins were successfully expressed and purified as shown in Additional file 1: Figure S1. MCF were isolated and cultured from rat heart. MCF were identified by positive-staining of vimentin and negative staining of endothelial cell and muscle markers vWF and desmin, respectively (Additional file 1: Figure S2).

To test the transduction efficiency of PEP-1-SOD1 fusion proteins into cardiac MCF, we used anti-His tag antibody to detect its protein level. As shown in Fig. 1a and $\mathrm{c}$, the fusion protein was observed in MCF $15 \mathrm{~min}$ after incubation with $2 \mu \mathrm{M}$ of PEP-1-SOD1, and the protein level gradually increased when the incubation time increased. However, incubation with SOD1 protein did not result in accumulation of SOD1 in the cells (data not shown). Moreover, the transduction of PEP-1-SOD1 fusion protein, but not SOD1, occurred in a dosedependent manner (Fig. $1 \mathrm{~b}$ and $\mathrm{d}$ ). To further confirm the transduction, PEP-1-SOD1 or SOD1 was conjugated to FITC fluorescein, and the transduction was observed by immunofluorescent microscopy after incubation with the cells. As shown in Fig. 1e, strong green fluorescent signals were observed in cells pretreated with PEP-1SOD1, but not with SOD1 protein, demonstrating that PEP-1-SOD1, but not SOD1, can enter cardiac myofibroblasts. Importantly, PEP-1-SOD1 is functionally active. As shown in Fig. 1f, SOD1 activity of PEP-1-SOD1 was 2.5-fold higher compared to the untransduced cells, and this high enzyme activity can last for $12-24 \mathrm{~h}$.

\section{PEP-1-SOD1 fusion protein decreased $\mathrm{O}_{2}^{-}$levels and MDA content while enhanced SOD activity}

To determine if PEP-1-SOD1 transduction blocks ROS in MCF, we used Ang II to induce ROS production. As shown in Fig. 2a-d, Ang II increased the production of 


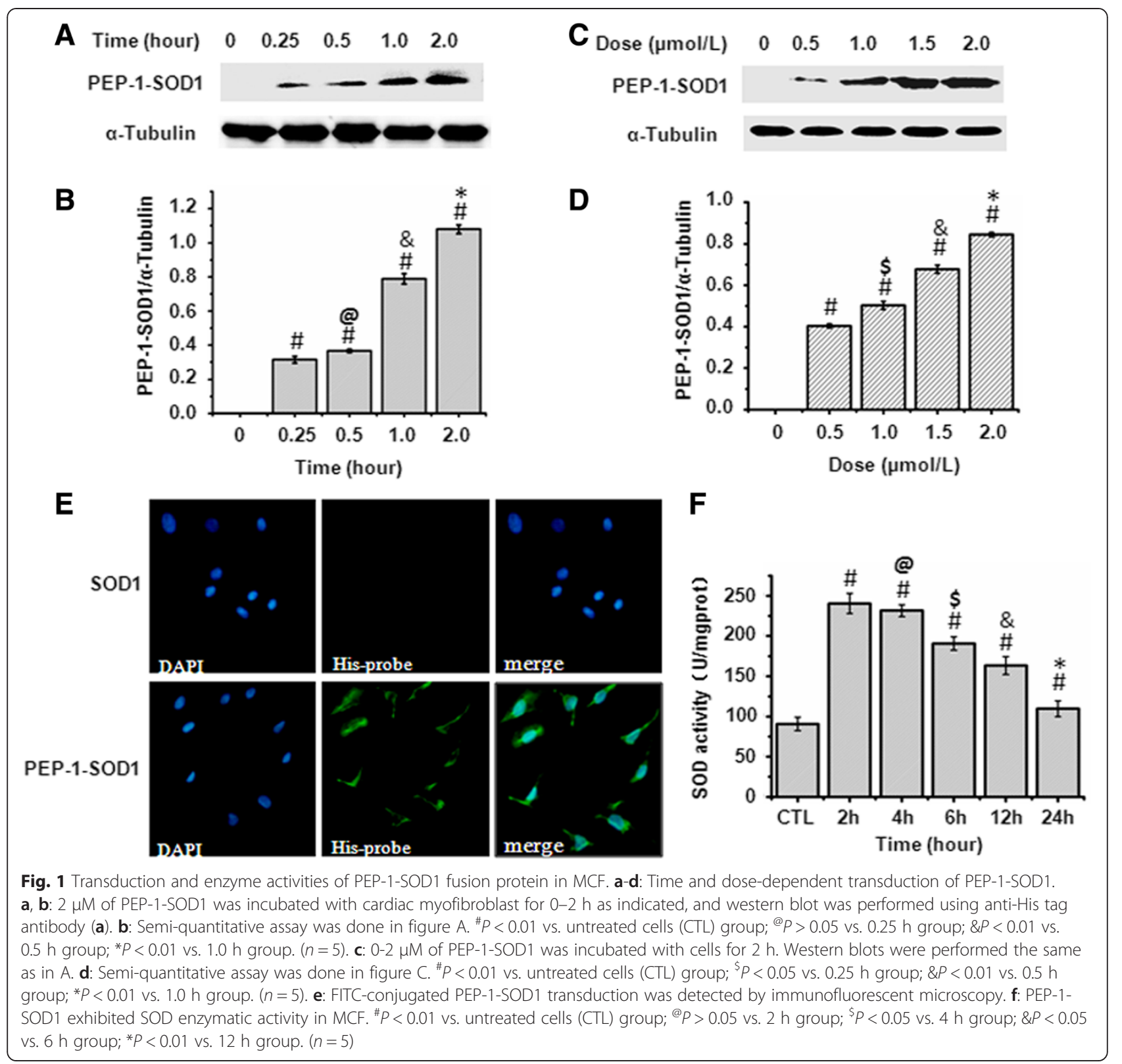

$\mathrm{O}_{2}^{-}$and MDA content while decreasing SOD activity in MCF. PEP-1-SOD1 fusion protein pretreatment, however, reduced Ang II-induced $\mathrm{O}_{2}^{-}$production and MDA content. PEP-1-SOD1 also enhanced SOD activity in cells. SOD1 pretreatment appeared to have no significant effects on the levels of $\mathrm{O}_{2}^{-}$, MDA content, or SOD activity mediated by Ang II. These results suggest that PEP1-SOD1 fusion protein transduction protects MCF from Ang II-induced ROS through the enhanced SOD activity. SOD1 transduction is clearly unable to increase the SOD1 activity in MCF. PEP-1-SOD1 specifically increased SOD1 activity, but did not affect NADPH oxidases because PEP-
1-SOD1 did not alter the expression of gp91 ${ }^{\text {phox }}$, a key subunit of NAPDH oxidases although Ang II also increased gp91 ${ }^{\text {phox }}$ expression (Fig. 2e-f). As expected, SOD1 transduction had no effect on Ang II-induced gp91 ${ }^{\text {phox }}$ expression (Fig. 2e-f).

\section{PEP-1-SOD1 fusion protein attenuated Ang II-induced MCF proliferation}

Ang II is a potent factor inducing MCF proliferation. We confirmed that Ang II promotes MCF proliferation (Fig. 3a). Pretreatment of SOD1 slightly, but transduction of PEP-1-SOD1 fusion proteins dramatically 


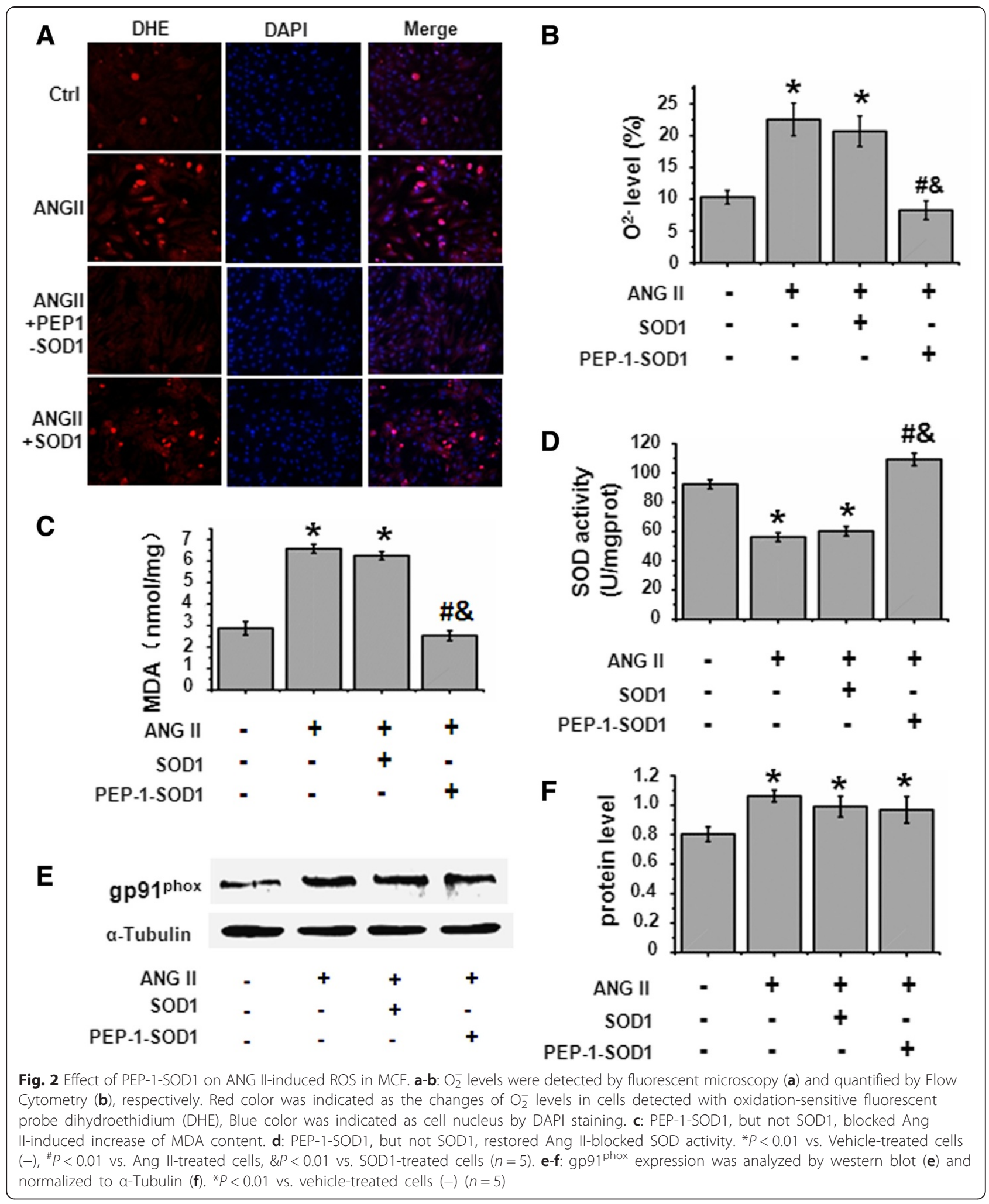

attenuated the Ang II-induced cell proliferation. Proliferating cell nuclear antigen (PCNA) is a biomarker of cell proliferation. To further determine the effect of PEP-1-
SOD1 fusion protein on MCF proliferation, we detected the PCNA expression. Ang II up-regulated PCNA expression (Fig. 3b-c). SOD1 transduction, slightly inhibited, but 

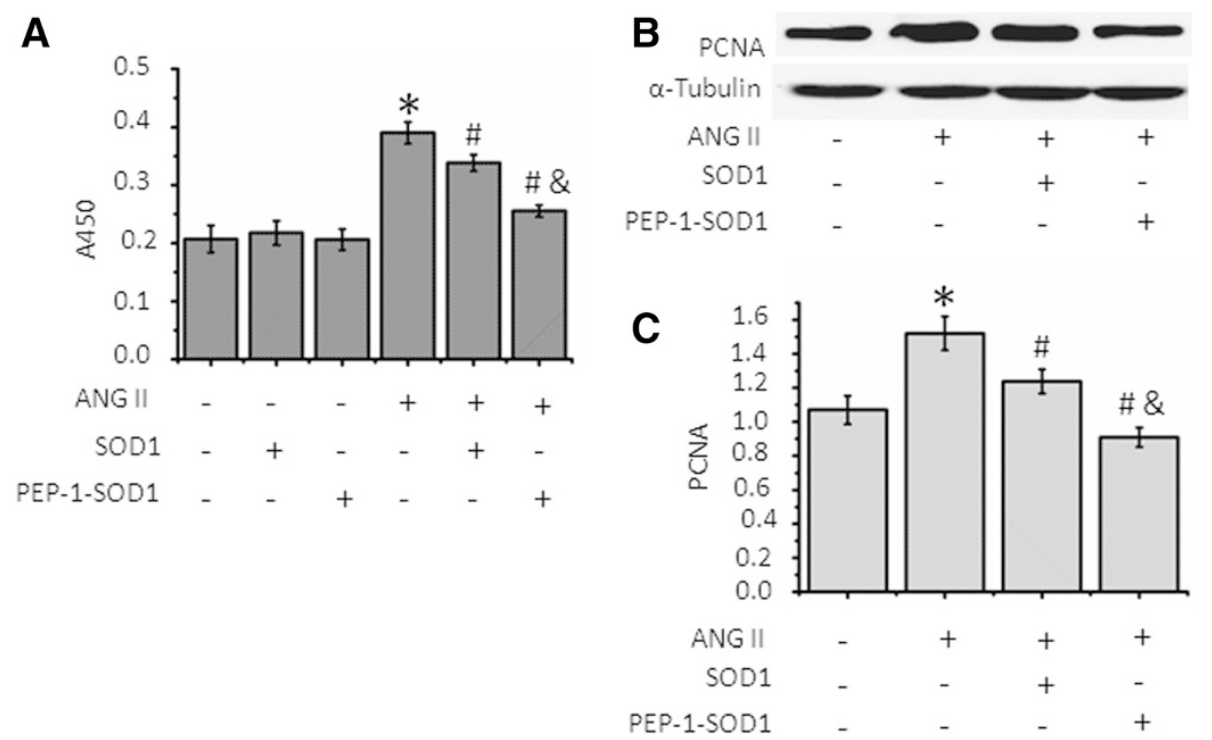

Fig. 3 Effect of PEP-1-SOD1 on Ang II-induced MCF proliferation. a, MCF proliferation was assayed with CCK-8. $\mathbf{b}-\mathbf{c}$, PCNA expression was measured by western blot (b) and quantified by normalizing to a-Tubulin (c). ${ }^{*} P<0.01$ vs. vehicle-treated cells $(-),{ }^{\#} P<0.01$ vs. Ang II-treated cells, \&P< 0.05 vs. SOD1-treated cells $(n=5)$

PEP-1-SOD1 fusion proteins dramatically blocked PCNA expression (Fig. $3 \mathrm{~b}-\mathrm{c}$ ). These results indicate that Ang II induces MCF proliferation through increasing ROS production, which can be diminished by the transduction of PEP-1-SOD1.

\section{PEP-1-SOD1 fusion protein attenuated Ang-II-induced MCF activation}

Excessive MCF activation accompanied by excessive collagen production is the main mechanism underlying the onset of cardiac fibrosis. Ang II markedly stimulated expression of smooth muscle $\alpha$-actin ( $\alpha$-SMA) and TGF$\beta 1$ in MCF (Fig. 4a-c), indicating a MCF activation. It is known that Ang II induces fibrosis through TGF- $\beta$ signaling pathway. SOD1 slightly reduced Ang II-induced $\alpha-S M A$ and TGF- $\beta$ expression. PEP-1-SOD1 infusion protein, however, dramatically blocked Ang II induction of these two genes (Fig. 4). Importantly, PEP-1-SOD1 had a much greater effect as compared to SOD1 (Fig. 4).

\section{PEP-1-SOD1 blocked Ang-II-induced production of type I and III collagen}

Activation of MCF leads to production of collagen. To determine if PEP-1-SOD1 fusion plays a role in collagen synthesis, we used Ang II to treat MCF and detected type I (Col I) and III collagen (Col III) protein expression, respectively. As shown in Fig. 5, both the Col I and Col III production were significantly increased over 2.5 fold by Ang II induction. SOD1 pretreatment of MCF marginally, while PEP-1-SOD1 pretreatment dramatically, suppressed
Ang-II-induced synthesis of both Col I and Col III (Fig. 5a-c). The effect of PEP-1-SOD1 was much greater compared to that of SOD1. These results demonstrated that delivery of PEP-1-SOD1 can effectively block the excessive production of collagen in activated MCF.

\section{PEP-1-SOD1 increased Ang-II-mediated blockade of MMP-1 secretion and increase of TIMP-1 production}

MMP-1 is a crucial enzyme degrading ECM, and TIMP1 is a key inhibitor of MMPs. The production of MMP-1 and TIMP-1 is associated with cardiac fibrosis. We found that Ang II reduced the MMP-1 secretion and stimulated production of TIMP-1 in MCF (Fig. 6a-b), consistent with the increased production of $\mathrm{Col} \mathrm{I}$ and Col III. Pretreatment of SOD1 only marginally reversed Ang II-mediated increase of MMP-1 and reduction of TIMP-1 (Fig. 6a-b). Pretreatment of PEP-1-SOD1, however, almost completely restored Ang II-blocked MMP-1 secretion, and dramatically inhibited Ang II-mediated increase of TIMP-1 secretion (Fig. 6a-b).

\section{Discussion}

Antioxidants have been shown to suppress cardiac fibrosis and improve cardiac function in animal models [15]. Therefore, antioxidant enzymes have been considered as promising therapeutic agents to prevent cardiac fibrosis. SOD1 is a key superoxide dismutase localized in the cytoplasm in mammalian tissues [16], and thus a potential agent for cardiac fibrosis therapy [17]. However, exogenous SOD1 is unable to penetrate into cells or organs to block 


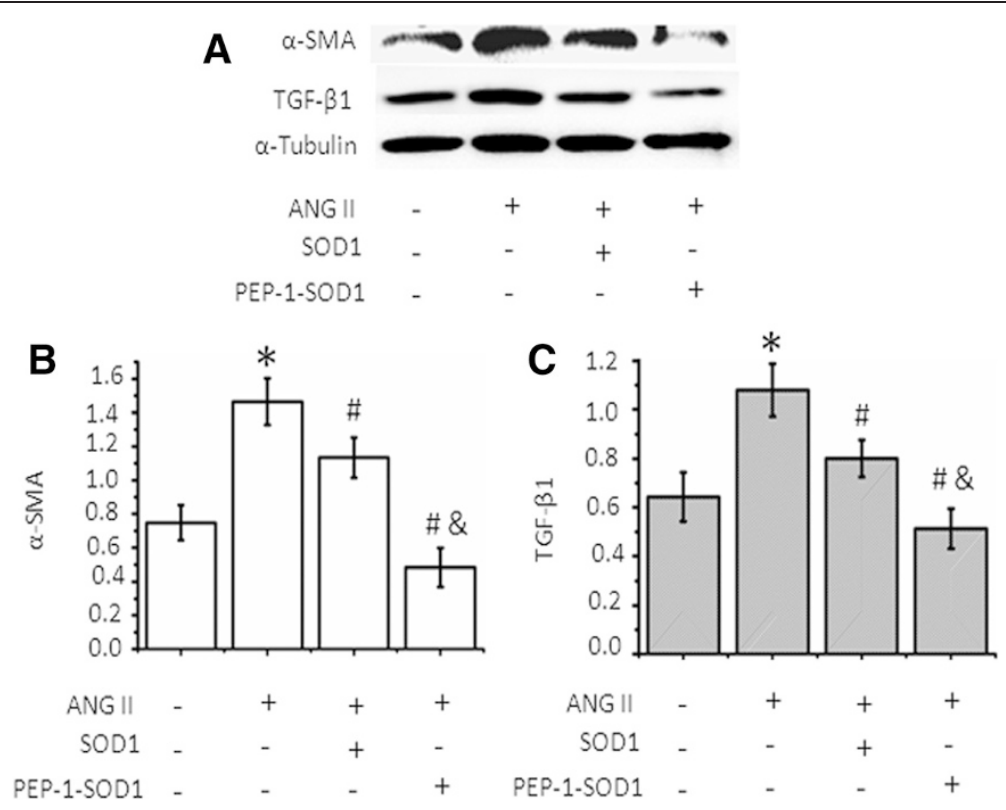

Fig. 4 Effect of PEP-1-SOD1 on a-SMA and TGF- $\beta 1$ protein expression. a a-SMA and TGF- $\beta 1$ protein expression was detected by western blot. b Quantification of a-SMA expression by normalizing to a-Tubulin. c Quantification of TGF- $\beta 1$ expression by normalizing to a-Tubulin. ${ }^{*} P<0.01$ vs. vehicle-treated cells, ${ }^{\#} P<0.01$ vs. Ang II-treated cells. $\& P<0.01$ vs. SOD1-transduced cells $n=5$

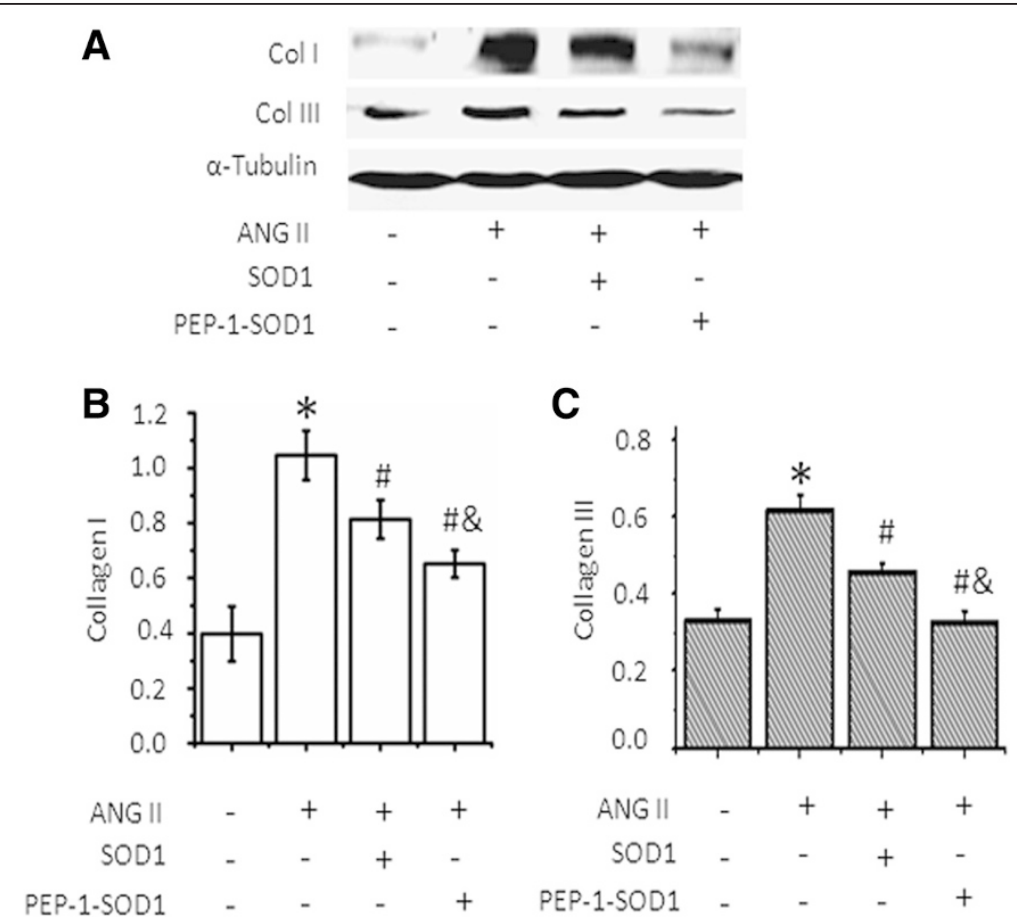

Fig. 5 Effect of PEP-1-SOD1 on type I (Col I) and III (Col III) collagen metabolism. a Col I and Col III production was analyzed with western blot. b Quantification of Col I by normalizing to a-Tubulin. c Quantification of Col I by normalizing to $a-T u b u l i n$. ${ }^{*} P<0.01$ vs. vehicle-treated cells, ${ }^{\#} P<0.01$ vs. Ang II-treated cells, $\& P<0.01$ vs. SOD1 transduced cells $n=5$ 

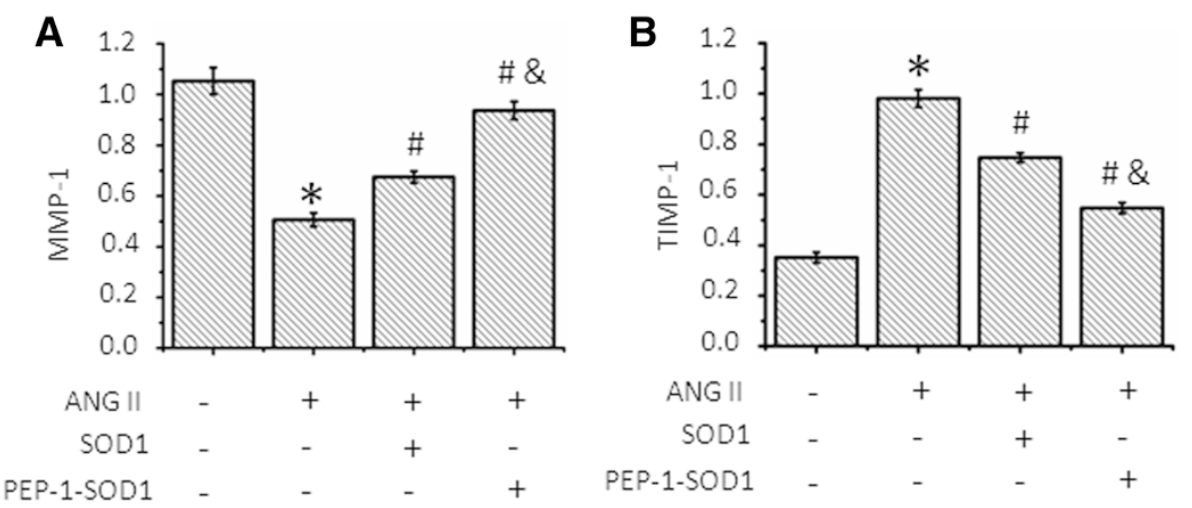

Fig. 6 Effect of PEP-1-SOD1 on matrix metalloproteinase-1 (MMP-1) and tissue inhibitors of metalloproteinase 1 (TIMP-1) secretion. The levels of MMP-1 (a) and TIMP-1 (b) in culture media were examined by ELISA. ${ }^{*} P<0.01$ vs. vehicle-treated cells, ${ }^{\#} P<0.01$ vs. Ang II-treated cells, \&P $<0.01$ vs. SOD1- transduced cells $n=5$

oxidative stress due to the lack of permeability. Although a number of approaches have been studied for delivering proteins into cells including lipid-, polycationic-, nanoparticle-, and peptide-based methods, these technologies is less effective in pre-clinical or clinical applications because of the poor stability of the complexes formed, the rapid degradation of cargos, or insufficient ability to reach its target. Cell-penetrating peptides are powerful tools used to improve cellular uptake of therapeutic molecules and show bright promise in the clinic application [18]. Our previous studies have demonstrated that PEP-1-SOD1 can be efficiently transduced into cardiomyocytes or neuron cells to prevent these cells from oxidative injury $[9,10,13]$. Our current study demonstrates that PEP-1-SOD1 can also be delivered into MCF and protect MCF from Ang II-induced transdifferentiation. Therefore, PEP-1-SOD1 may be used as a potential therapeutics to treat cardiac fibrosis.

MCF proliferation and activation are the main factors contributing to cardiac fibrosis. Ang II appears to promote both the proliferation and activation because Ang II stimulates MCF growth, PCNA expression, and myofibroblast marker $\alpha$-SMA expression [19-21]. Although SOD1 transduction only marginally attenuates Ang II function in MCF proliferation and activation, PEP-1SOD1 exhibits a dramatic effect in blocking Ang II activity. In addition, PEP-1-SOD1 blocks collagen production that is induced by Ang II, suggesting that PEP-1-mediated SOD1 delivery are multi-functional in MCF, i.e., regulating MCF proliferation, differentiation and ECM production. Mechanistically, PEP-1-SOD1 appears to regulate collagen production by modulating MMP1 and TIMP-1 expression because PEP-1-SOD1 reverses Ang II-induced downregulation of MMP1 and upregulation of TIMP-1. Therefore, PEP-1-SOD1 is likely to block TIMP-1 expression, causing increased MMP1 expression. The increased MMP1 then degrades excessive collagen production, leading to the resolution of fibrosis.
Interestingly, although we are unable to detect the SOD1 transduction or activity in MCF, pretreatment with SOD1 exhibits a slight but significant effect on Ang II-induced expression of $\alpha$-SMA, TGF- $\beta$, Col I, Col II, MMP1, and TIMP-1. This is likely due to SOD1 activity in improving ROS status in extracellular environment $[22,23]$. It is also possible that SOD1 may slightly affect Ang II interaction with its receptor although the interference does not produce a major impact to Ang II activity. This potential mechanism is obviously a interesting subject for future study.

\section{Conclusion}

Our study show that PEP-1-SOD1 fusion protein can be successfully delivered into MCF to scavenge ROS production and block collagen production, suggesting that PEP-1-SOD1 may be a promising therapeutic agent for treating ROS-mediated cardiac fibrosis.

\section{Additional file}

\begin{abstract}
Additional file 1: Figure S1. Expression and purification of SOD1 and PEP-1-SOD1 fusion proteins. Protein extracts and the purified fusion proteins were resolved in 12\% SDS-PAGE (A) and subjected to Western blot analysis with rabbit anti-His-tag antibody (B). Lane 1: pre-stained protein marker; lane 2: total protein extracts for SOD1, lane 3: purified SOD1 proteins; lane 4: total protein extracts for PEP-1-SOD1; lane 5: purified PEP-1-SOD1 fusion proteins. Figure S2. Identification of cardiac myofibroblasts. Rat cardiac myofibroblasts were identified by positive staining with anti-vimentin and negative staining with anti-desmin and anti-vWF antibodies. (DOCX $176 \mathrm{~kb}$ )
\end{abstract}

\section{Abbreviations}

PEP-1: Cell-penetrating peptide 1; SOD1: Copper, zinc-superoxide dismutase; ANG II: Angiotensin II; MCF: Cardiac myofibrolast ; MMP-1: Matrix metalloproteinases 1; TIMP-1: Tissue inhibitor of metalloproteinases 1; TGF$\beta 1$ : Transforming growth factor- $\beta 1$; a-SMA: Smooth muscle a-actin; ECM: Extracellular matrix; ROS: Reactive oxygen species; IPTG: isopropyl- $\beta-D-$ thiogalactoside; DMEM: Dulbecco's modified essential media; WF: Von Willebrand factor; MDA: Malondialdehyde; $\mathrm{O}^{2-}$ : Superoxide anion; 
PCNA: Proliferating cell nuclear antigen; gp91 phox: Cytochrome b-245, beta polypeptide; Col I: Collagen type I; Col III: Collagen type III.

\section{Competing interests}

LGT is an employee of Department of Cardiology and WJN received National Natural Science Foundation of China. All authors declare that they have no competing interests.

\section{Authors' contributions}

LGT has made substantial contributions to conception and design of the study, and carried out the cell experimental studies participated in MMP-1 and TIMP-1 ELISA assay and drafted the manuscript. JHX carried out MDA and SOD1 measurement, and has made substantial contributions to conception and design of the study. DLY carried out MMT assay. LZ participated in cell culture and PEP1-SOD1 protein purification. FZ carried out Western Blotting assay. YJY participated in immunofluorescence assay. LYG carried out PEP1-SOD1 protein purification. JMT participated in drafting and interpretation. JNW participated in drafting and interpretation and has made substantial contributions to conception and design of the study of data. SYC has made substantial contributions to conception and design of the study of data and critically revised the manuscript. All authors read and approved the final manuscript.

\section{Authors' information}

Not applicable

\section{Acknowledgement}

This work was supported by grants from National Natural Science Foundation of China (81270221 to J.-N.W., 81328002 to S.-Y.C. and 81170095.to J.-M. T), and National Institutes of Health (HL123302, HL119053, and HL107526 to S.-Y.C.).

\section{Author details}

${ }^{1}$ Institute of Clinical Medicine, Renmin Hospital, Hubei University of Medicine, Shiyan, Hubei 442000, P. R. China. ${ }^{2}$ Department of Cardiology, Renmin Hospital, Hubei University of Medicine, Shiyan, Hubei 442000, P. R. China. ${ }^{3}$ Department of Emergency, Renmin Hospital, Hubei University of Medicine, Shiyan, Hubei 442000, P. R. China. ${ }^{4}$ Departments of Physiology and Pharmacology, University of Georgia, Athens, GA 30622, USA.

Received: 22 December 2014 Accepted: 21 September 2015 Published online: 07 October 2015

\section{References}

1. Souders CA, Bowers SL, Baudino TA. Cardiac fibroblast: the renaissance cell. Circ Res. 2009;105(12):1164-76.

2. Zhao W, Ahokas RA, Weber KT, Sun Y. ANG Il-induced cardiac molecular and cellular events: role of aldosterone. Am J Physiol Heart Circ Physiol. 2006;291 (1):H336-43.

3. Doehner W, Schoene N, Rauchhaus M, Leyva-Leon F, Pavitt DV, Reaveley DA, et al. Effects of xanthine oxidase inhibition with allopurinol on endothelial function and peripheral blood flow in hyperuricemic patients with chronic heart failure: results from 2 placebo-controlled studies. Circulation. 2002;105(22):2619-24.

4. Lijnen PJ, van Pelt JF, Fagard RH. Stimulation of reactive oxygen species and collagen synthesis by angiotensin II in cardiac fibroblasts. Cardiovasc Ther. 2012;30(1):e1-8.

5. van Empel VP, Bertrand AT, van Oort RJ, van der Nagel R, Engelen M, van Rijen HV, et al. EUK-8, a superoxide dismutase and catalase mimetic, reduces cardiac oxidative stress and ameliorates pressure overload-induced heart failure in the harlequin mouse mutant. J Am Coll Cardiol. 2006;48(4):824-32.

6. Siwik DA, Pagano PJ, Colucci WS. Oxidative stress regulates collagen synthesis and matrix metalloproteinase activity in cardiac fibroblasts. Am J Physiol Cell Physiol. 2001;280(1):C53-60.

7. Lijnen PJ, van Pelt JF, Fagard RH. Downregulation of manganese superoxide dismutase by angiotensin II in cardiac fibroblasts of rats: Association with oxidative stress in myocardium. Am J Hypertens. 2010;23(10):1128-35.

8. Morris MC, Depollier J, Mery J, Heitz F, Divita G. A peptide carrier for the delivery of biologically active proteins into mammalian cells. Nat Biotechnol. 2001;19(12):1173-6.
9. Zhang YE, Fu SZ, Li XQ, Chen P, Wang JL, Che J, et al. PEP-1-SOD1 protects brain from ischemic insult following asphyxial cardiac arrest in rats. Resuscitation. 2011;82(8):1081-6.

10. Huang $G Q$, Wang JN, Tang JM, Zhang L, Zheng F, Yang JY, et al. The combined transduction of copper, zinc-superoxide dismutase and catalase mediated by cell-penetrating peptide, PEP-1, to protect myocardium from ischemia-reperfusion injury. J Transl Med. 2011;9:73.

11. Zhang YE, Wang JN, Tang JM, Guo LY, Yang JY, Huang YZ, et al. In vivo protein transduction: delivery of PEP-1-SOD1 fusion protein into myocardium efficiently protects against ischemic insult. Mol Cells. 2009;27(2):159-66.

12. Agocha $A E$, Eghbali-Webb M. A simple method for preparation of cultured cardiac fibroblasts from adult human ventricular tissue. Mol Cell Biochem. 1997;172(1-2):195-8.

13. Zhang L, Wei S, Tang JM, Guo LY, Zheng F, Yang JY, et al. PEP-1-CAT protects hypoxia/reoxygenation-induced cardiomyocyte apoptosis through multiple sigaling pathways. J Transl Med. 2013;11:113.

14. Zhang L, Wang JN, Tang JM, Kong $X$, Yang JY, Zheng F, et al. VEGF is essential for the growth and migration of human hepatocellular carcinoma cells. Mol Biol Rep. 2012;39:5085-93.

15. Zhou SX, Zhou Y, Zhang YL, Lei J, Wang JF. Antioxidant probucol attenuates myocardial oxidative stress and collagen expressions in post-myocardial infarction rats. J Cardiovasc Pharmacol. 2009;54(2):154-62.

16. Zhan CD, Sindhu RK, Pang J, Ehdaie A, Vaziri ND. Superoxide dismutase, catalase and glutathione peroxidase in the spontaneously hypertensive rat kidney: effect of antioxidant-rich diet. J Hypertens. 2004;22(10):2025-33.

17. Lijnen P, Petrov V, van Pelt J, Fagard R. Inhibition of superoxide dismutase induces collagen production in cardiac fibroblasts. Am J Hypertens. 2008;21(10):1129-36.

18. Morris MC, Deshayes S, Heitz F, Divita G. Cell-penetrating peptides: from molecular mechanisms to therapeutics. Biol Cell. 2008;100(4):201-17.

19. Cheng TH, Leung YM, Cheung CW, Chen CH, Chen YL, Wong KL. Propofol depresses angiotensin II-induced cell proliferation in rat cardiac fibroblasts. Anesthesiology. 2010;112(1):108-18.

20. Olson ER, Shamhart PE, Naugle JE, Meszaros JG. Angiotensin II-induced extracellular signal-regulated kinase $1 / 2$ activation is mediated by protein kinase Cdelta and intracellular calcium in adult rat cardiac fibroblasts. Hypertension. 2008;51(3):704-11.

21. Lijnen P, Papparella I, Petrov V, Semplicini A, Fagard R. Angiotensin IIstimulated collagen production in cardiac fibroblasts is mediated by reactive oxygen species. J Hypertens. 2006;24(4):757-66.

22. Mollnau H, Wenzel P, Oelze M, Treiber N, Pautz A, Schulz E, et al. Mitochondrial oxidative stress and nitrate tolerance - comparison of nitroglycerin and pentaerithrityl tetranitrate in $\mathrm{Mn}-\mathrm{SOD}+$ /- mice. BMC Cardiovasc Disord. 2006;6:44.

23. Liu SS, Wang HY, Tang JM, Zhou XM. Hypoxia-induced collagen synthesis of human lung fibroblasts by activating the angiotensin system. Int J Mol Sci. 2013;14(12):24029-45.

\section{Submit your next manuscript to BioMed Central and take full advantage of:}

- Convenient online submission

- Thorough peer review

- No space constraints or color figure charges

- Immediate publication on acceptance

- Inclusion in PubMed, CAS, Scopus and Google Scholar

- Research which is freely available for redistribution 